\title{
Annual and regional variability in adult Dasineura mali (apple leafcurling midge) emergence in New Zealand
}

\author{
P.L. Lo and J.T.S. Walker \\ The New Zealand Institute for Plant \& Food Research Limited, Private Bag 1401, \\ Havelock North 4157, New Zealand \\ Corresponding author: peter.lo@plantandfood.co.nz
}

\begin{abstract}
Apple leafcurling midge is an important quarantine pest for New Zealand apple exports. Season-long pheromone trapping was conducted in Hawke's Bay and Nelson from 2004-2017, and from 2012-2017 in Central Otago. Four generations occurred annually in Hawke's Bay and Nelson and 3-4 in Central Otago. In Hawke's Bay and Nelson, the timing of each peak varied by about 3-4 weeks between years, while the difference was $\sim 2-3$ weeks in Central Otago during fewer years of monitoring. Hawke's Bay was up to a month earlier than Central Otago for the same peak within individual years. The major factor behind this variability was the accumulated number of growing degree-days. Insecticide sprays target midge larvae, but are timed against the second and third peaks of adult emergence. Variations in the timing of these peaks annually and across the main pipfruit growing regions, mean that specific insecticide timing recommendations are necessary each year for each region.
\end{abstract}

Keywords Cecidomyiidae, Dasineura mali, apple, phenology.

\section{INTRODUCTION}

Apple leafcurling midge (ALCM, Dasineura mali) is a phytosanitary pest of export apple crops. When mature larvae emerge from leaves to pupate, a small proportion lodge and pupate in the calyx or stem end of the fruit. This contamination of apples, albeit at a low incidence, complicates access to several important export markets such as Australia, China, Japan and Taiwan, worth over \$NZ200M (Anon. 2015). The phytosanitary requirements to access these markets necessitates a high degree of ALCM control.

Apple leafcurling midge has four generations per year between early spring and mid-autumn throughout most of New Zealand (Smith \& Chapman 1997; He \& Wang 2011; Lo et al. 2015). The exception is Central Otago where three or four generations occur depending on summer temperatures (Wearing et al.2013). Adults emerge from the soil litter and mate immediately. Eggs are laid on unfurling leaves of actively growing shoots and hatch within a few days. Feeding by larvae causes the leaf edges to become tightly rolled. Larvae develop for 2-3 weeks within these rolls where they are well protected from contact insecticides. Once mature, the larvae drop from the rolls in search of a protected place to pupate. The third adult emergence period occurs in January or February, just before harvest, and it is the larvae from this generation that infest fruit. An increasing proportion of each generation goes into diapause and ALCM overwinters as mature larvae in the soil (He et al. 2010). 
Effective management of ALCM in New Zealand is dependent on the development of a systems approach using a suite of on- and offorchard control tactics to reduce fruit infestation. The insecticide spirotetramat $\left(\right.$ Movento $^{\circledR}$, Bayer CropScience) is widely used by growers for ALCM control. This systemic chemical is translocated both up and down within plants (Nauen et al. 2008) and is active against larvae but it has no toxicity to adults and eggs. Other ALCM suppression strategies include a selective pest management programme that helps to maximise biological control from predators and the parasitoid Platygaster demades. Growers also use deficit irrigation to reduce shoot growth and avoid blocks that have high vigour or a history of large infestations to minimise the risk of fruit infestation. Post-harvest apple washers are also used to remove a high proportion of cocoons (D.J. Rogers unpubl. data). Together, these practices ensure that a high proportion of crops meet the most demanding phytosanitary requirements.

The New Zealand apple industry is centred in Hawke's Bay (70\% of export production in 2016) and Nelson (22\%), while Central Otago is the third largest production area (4\%) (Anon. 2017). Hawke's Bay (latitude $39^{\circ} \mathrm{S}$ ) is in the North Island, while Nelson (latitude $41^{\circ} \mathrm{S}$ ) and Central Otago (latitude $45^{\circ} \mathrm{S}$ ) are in the South Island.

The female-produced ALCM sex pheromone was identified as (Z)-13-acetoxy-8-heptadecen2-one (Hall \& Cross 2006). It has been synthesised and developed for pest monitoring since 2004 (Cross \& Hall 2009, Cross et al. 2009). The availability of the pheromone has enabled ALCM activity and phenology to be monitored in New Zealand apple orchards. The objective of this study was to determine the extent of annual and regional variability of ALCM phenology in the three main apple production regions of New Zealand.

\section{METHODS}

Monitoring of ALCM populations with pheromone traps began in Hawke's Bay and Nelson in 2004. In Hawke's Bay, initially four orchards were monitored and this was later increased to seven orchards per year. Two of the original properties were monitored every year, while others had to be replaced because trees were removed or production methods changed. Four orchards were also initially monitored in Nelson, subsequently expanding to five, and three of the original blocks were monitored throughout the study. One orchard in Central Otago has been monitored since 2012 to increase the regional spread of data.

Two delta traps each with a 3- $\mu$ g pheromone lure (Cross \& Hall 2009) were hung in each orchard $50-80 \mathrm{~cm}$ above the ground between September and April each year. They were checked weekly although since 2012-13, at times approaching peaks of adult emergence, traps were checked twice per week in Hawke's Bay and Nelson. At each check the sticky base was replaced and the used one brought back to the laboratory to count ALCM. A subsample of the base was counted when numbers were large.

The mean date for each peak in each year for Hawke's Bay and Nelson was calculated from the dates that the peak occurred on the individual orchards. If the mean date had been based on the counts of midges, this would have biased it towards orchards that had the largest catches. The cumulative number of growing degree-days (GDD, base $7^{\circ} \mathrm{C}$ ) from 1 July for these dates were obtained from weather stations in each region closest to the monitored orchards. The mean GDDs were calculated from stations at Havelock North and Pakowhai for Hawke's Bay and from the Riwaka and Landsdowne Road stations for Nelson. The Clyde station provided GDDs for Central Otago. The GDD data were correlated against dates of peak ALCM emergence for each region. This produced approximate $r$ values because the measures after the first emergence period were not independent.

\section{RESULTS}

Apple leafcurling midge typically had four welldefined periods of adult emergence per year in each region, although occasionally an early or late peak was obscured or absent. Figure 1 displays data from 2015-16 to illustrate the differences 


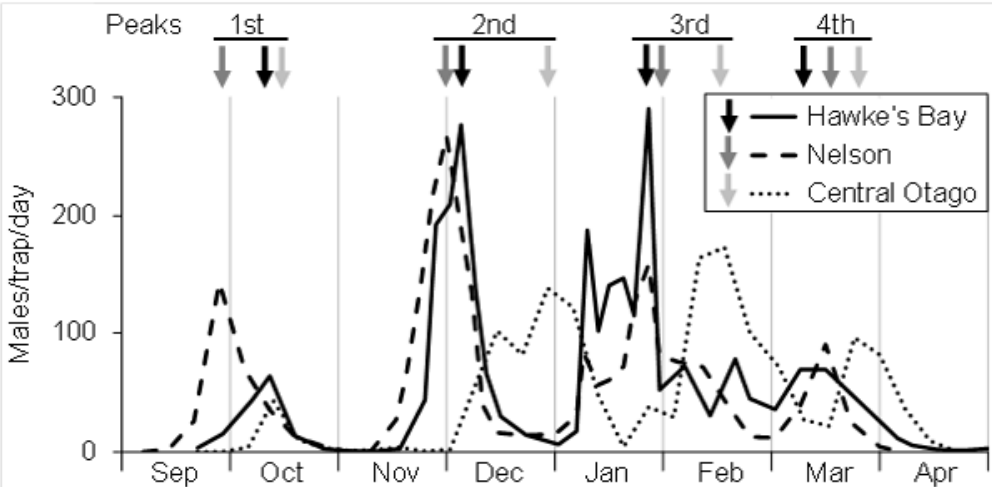

Figure 1 Mean pheromone trap catches of male apple leafcurling midge in apple orchards in three regions, 2015-16.

in phenology amongst the regions. The size and heights of the peaks varied greatly from year to year, but the second and third peaks were always the largest, while the first and fourth peaks were typically small. Hawke's Bay usually had earlier peaks than the other two regions, although the 2015-16 season was unusual because the first two peaks were earliest in Nelson. In that season, the first two peaks in Hawke's Bay were relatively late whereas those in Nelson occurred close to their average dates.

During the past 13 years, the timing of the four annual peaks has varied greatly both within and amongst the three regions (Table 1). The dates of the mean occurrence of the peaks follow latitude with Hawke's Bay earliest and Nelson two days after for peak 1 and 1-2 weeks later for peaks 2-4. The average dates in Central Otago were behind those in Hawke's Bay by 11 days for the first peak and by about one month for the others (Table 1).

The occurrence of each peak varied by approximately 3-4 weeks in general during the 13-year monitoring period in Hawke's Bay and Nelson. There was a narrower span of days in Central Otago, which was not surprising given the fewer years of monitoring. The duration of the second and third peaks (measured from trough to trough) averaged approximately 7-8 weeks in all three regions. The yearly dates were most tightly clustered around the means of peak
1 and became more dispersed for other peaks as the season progressed.

The number of days between successive peaks decreased during the season in each region (Table 2). The same trend did not apply to GDDs, for which the interval increased progressively from peak 2 to peak 4 in Hawke's Bay, whereas in Nelson and Central Otago the largest interval was between peaks 2 and 3. The correlations $(r)$ between the cumulative GDDs and the dates of peak emergence in each region were as follows: 0.984 Hawke's Bay, 0.986 Nelson, 0.984 Central Otago.

\section{DISCUSSION}

There has been a substantial variation in the dates of ALCM adult emergence peaks during the past 13 years. The critical second and third peaks have occurred within a 3-4 week window in both Hawke's Bay and Nelson. The rate of insect development is closely linked to temperature within lower and upper limits for each species (Ratte 1984), so it was expected that the dates of peak emergence would be strongly correlated with the accumulation of growing degree-days. Regional differences in growing degree-days also accounted for the one month delay between peaks $2-4$ in Central Otago compared with Hawke's Bay. Tomkins et al. (2000) measured emergence of the first generation over two years 
Table 1 Variation in dates of peak catches of apple leafcurling midge in pheromone traps, and the mean duration of the second and third emergence periods, in the main apple production regions of New Zealand.

\begin{tabular}{|c|c|c|c|c|c|}
\hline $\begin{array}{l}\text { Region (Sampling } \\
\text { period) }\end{array}$ & Peak & 1 & 2 & 3 & 4 \\
\hline \multirow{6}{*}{$\begin{array}{l}\text { Hawke’s Bay } \\
(2004-17)\end{array}$} & Earliest & $21 \mathrm{Sep}$ & 17 Nov & $31 \mathrm{Dec}$ & $18 \mathrm{Feb}$ \\
\hline & Latest & $15 \mathrm{Oct}$ & $6 \mathrm{Dec}$ & 26 Jan & $16 \mathrm{Mar}$ \\
\hline & Mean & 30 Sep & $25 \mathrm{Nov}$ & 12 Jan & $27 \mathrm{Feb}$ \\
\hline & St. dev. (days) & 6.3 & 6.4 & 7.2 & 8.2 \\
\hline & Span (days) & 24 & 19 & 26 & 26 \\
\hline & Duration (days) & - & 49 & 49 & - \\
\hline \multirow{6}{*}{$\begin{array}{l}\text { Nelson } \\
(2004-17)\end{array}$} & Earliest & 26 Sep & 23 Nov & 13 Jan & $14 \mathrm{Feb}$ \\
\hline & Latest & $14 \mathrm{Oct}$ & $16 \mathrm{Dec}$ & 9 Feb & $25 \mathrm{Mar}$ \\
\hline & Mean & 2 Oct & $1 \mathrm{Dec}$ & 25 Jan & 5 Mar \\
\hline & St. dev. (days) & 6.2 & 6.6 & 8.0 & 11.9 \\
\hline & Span (days) & 18 & 23 & 26 & 39 \\
\hline & Duration (days) & - & 59 & 52 & - \\
\hline \multirow{6}{*}{$\begin{array}{l}\text { Central Otago } \\
(2012-17)\end{array}$} & Earliest & $6 \mathrm{Oct}$ & $18 \mathrm{Dec}$ & $5 \mathrm{Feb}$ & $18 \mathrm{Mar}$ \\
\hline & Latest & $16 \mathrm{Oct}$ & $30 \mathrm{Dec}$ & $18 \mathrm{Feb}$ & $8 \mathrm{Apr}$ \\
\hline & Mean & 11 Oct & $24 \mathrm{Dec}$ & $14 \mathrm{Feb}$ & 29 Mar \\
\hline & St. dev. (days) & 4.4 & 4.8 & 6.1 & 10.6 \\
\hline & Span (days) & 10 & 12 & 13 & 20 \\
\hline & Duration (days) & - & 55 & 51 & - \\
\hline
\end{tabular}

Table 2 Interval in days and growing degree-days $\left(\mathrm{GDD}\right.$, base $\left.7^{\circ} \mathrm{C}\right)$ between mean dates of peak catches of apple leafcurling midge in pheromone traps in three regions.

\begin{tabular}{|c|c|c|c|c|c|c|c|}
\hline \multirow[t]{2}{*}{ Region } & \multirow[t]{2}{*}{ Peaks } & \multicolumn{3}{|c|}{ Days } & \multicolumn{3}{|c|}{ GDD } \\
\hline & & Mean & St. dev. & Range & Mean & St. dev. & Range \\
\hline \multirow[t]{3}{*}{ Hawke’s Bay ${ }^{1}$} & $1 \& 2$ & 55.9 & 9.5 & $36-70$ & 391 & 61.3 & $292-520$ \\
\hline & $2 \& 3$ & 47.7 & 5.7 & $40-58$ & 505 & 71.0 & $403-638$ \\
\hline & $3 \& 4$ & 46.0 & 4.7 & $39-55$ & 534 & 58.3 & 449-619 \\
\hline \multirow[t]{3}{*}{ Nelson $^{2}$} & $1 \& 2$ & 60.1 & 9.2 & $42-73$ & 406 & 71.7 & $312-582$ \\
\hline & $2 \& 3$ & 55.2 & 6.6 & $44-66$ & 570 & 57.2 & $490-658$ \\
\hline & $3 \& 4$ & 38.8 & 9.2 & $25-59$ & 428 & 100.7 & $287-628$ \\
\hline \multirow[t]{3}{*}{ Central Otago $^{3}$} & $1 \& 2$ & 73.8 & 3.1 & $70-77$ & 490 & 52.6 & $420-565$ \\
\hline & $2 \& 3$ & 51.8 & 6.9 & $43-61$ & 507 & 51.9 & $442-577$ \\
\hline & $3 \& 4$ & 43.4 & 7.3 & $35-55$ & 379 & 54.0 & $304-449$ \\
\hline
\end{tabular}

Data from weather stations at: ${ }^{1}$ Havelock North \& Pakowhai $2004-17,{ }^{2}$ Riwaka \& Landsdowne Road 2004-17, ${ }^{3}$ Clyde 2012-17. 
in five regions. It occurred at a similar time in Waikato, Hawke's Bay and Nelson, but was later in Canterbury and Central Otago. Cross et al. (2009) who studied ALCM in Nelson, Italy and the UK, found that the adjusted date of peak catches increased approximately linearly with increasing latitude between $41-51^{\circ}$.

The GDD intervals varied between successive peaks in each region. This suggested that some factor in addition to temperature was influencing the phenology of ALCM. That factor was likely to be rainfall, because ALCM can remain as mature larvae waiting for sufficient moisture before exiting the leaf rolls (Barnes 1948). Periods of dry weather were observed to affect midge phenology by delaying the emergence of larvae (J.T.S. Walker unpubl. data).

Apple growers currently target insecticide sprays against the second and third adult ALCM emergence periods. Applying spirotetramat at or just after the peak was the most effective timing (P.L. Lo unpubl. data). This reduced fruit infestation more than sprays applied two weeks earlier or two weeks later. The third peak was always the largest during the seven years before the introduction of spirotetramat in 2011, but since then peak 2 was often bigger than peak 3 (P.L. Lo unpubl. data). For resistancemanagement purposes, it is recommended that no more than two spirotetramat sprays are applied per season (T.J.B. Herman, Pipfruit New Zealand pers. comm.).

The annual variation of peak dates within regions and the 7-8 week duration of the second and third periods has important implications for the timing of insecticide sprays. Spirotetramat is considered to have a three week period of efficacy within plants (L. Roberts, Bayer CropScience pers. comm.). Therefore one spirotetramat application cannot be effective over the whole of each generation. If growers were to apply Spirotetramat by calendar date, it is feasible that the main emergence date could be missed completely.

Differences in the phenology of ALCM from year to year and across the pipfruit growing regions indicates that specific insecticide timing recommendations will be necessary each year for each region for control to be maximised. A phenology model is being developed which is expected to reduce or eliminate the current annual trapping effort.

\section{ACKNOWLEDGEMENTS}

We thank the growers who gave us permission to use their orchards for the monitoring programme. Many people have helped with checking traps and the onerous task of counting hundreds of thousands of midges. Particular thanks go to Bernie Attfield, Lyn Cole, Kate Colhoun, Peter Shaw, Tara Taylor and Roger Wallis. Funding was provided by several programmes with the New Zealand Ministry for Science and Innovation and Pipfruit New Zealand Inc. The University of Greenwich, UK, holds a patent on the ALCM pheromone and this research was possible through their co-operation.

\section{REFERENCES}

Anon. 2015. Fresh Facts New Zealand Horticulture 2015. The New Zealand Institute for Plant \& Food Research Limited, 36 p.

Anon. 2017. Pipfruit New Zealand Incorporated. Statistical Annual 2016. Pipfruit New Zealand Incorporated $27 \mathrm{p}$.

Barnes HP 1948. Gall midges of economic importance. Vol 3: Gall Midges of Fruit. London: Crosby Lockwood \& Son Ltd.

Cross JV, Hall DR 2009. Exploitation of the sex pheromone of apple leaf midge Dasineura mali Kieffer (Diptera: Cecidomyiidae) for pest monitoring: Part 1. Development of lure and trap. Crop Protection 28: 139-144.

Cross JV, Hall DR, Shaw P, Anfora G 2009. Exploitation of the sex pheromone of apple leaf midge Dasineura mali Kieffer (Diptera: Cecidomyiidae) for pest monitoring: Part 2. Use of sex pheromone traps for pest monitoring. Crop Protection 28: 128-133.

Hall DR, Cross JV 2006. Semiochemicals in Management of Apple Leaf Midge Final report of Defra project HH3114TTF. Available from: http://www.defra.gov.uk/science/Project_ Data/DocumentLibrary/HH3 114 TTF/ HH3114TTF_3999_FRP.doc, 23 p. 
He XZ, Wang Q, Walker JTS, Rogers DJ, Lo PL 2010. A sophisticated life history strategy in a parasitoid wasp: Producing univoltine and multivoltine phenotypes in a local population. Biological Control 54: 276-284.

He XZ, Wang Q 2011. Phenological dynamics of Dasineura mali (Diptera: Cecidomyiidae) and its parasitoid Platygaster demades (Hymenoptera: Platygasteridae) in apple orchards. Journal of Economic Entomology 104: 1640-1646.

Lo PL, Walker JTS, Suckling DM 2015. Prospects for control of apple leaf midge Dasineura mali (Diptera: Cecidomyiidae) by mass trapping with pheromone lures. Pest Management Science 71: 907-913.

Nauen R, Reckmann U, Thomzik J, Thielert W 2008. Biological profile of spirotetramat (Movento ${ }^{\circledR}$ ) - a new two-way systemic (ambimobile) insecticide against sucking pest species. Bayer CropScience Journal 61: 245-277.
Ratte HT 1984. Temperature and insect development. In: Hoffmann $\mathrm{KH}$ ed. Environmental Physiology and Biochemistry of Insects. Springer Berlin Heidelberg. Pp. 33-66.

Smith JT, Chapman B 1997. Apple leafcurling midge egg laying on different apple cultivars and orchard properties on the Waimea plains, Nelson. Proceedings of the $50^{\text {th }}$ New Zealand Plant Protection Conference: 247-251.

Tomkins AR, Wilson DJ, Thomson C, Bradley S, Cole L, Shaw P, Gibb A, Suckling DM, Marshall R, Wearing CH 2000. Emergence of apple leafcurling midge (Dasineura mali) and its parasitoid (Platygaster demades). New Zealand Plant Protection 53: 179-84.

Wearing CH, Marshall RR, Attfield B, Colhoun C 2013. Phenology and distribution of the apple leafcurling midge (Dasineura mali (Kieffer) (Diptera: Cecidomyiidae) and its natural enemies on apples under biological and integrated pest management in Central Otago, New Zealand. New Zealand Entomologist 36: 87-106. 